\title{
Analysis on the 30-year Development of Research about Chinese Ideological and Political Education Rules
}

\author{
Li Xiaojuan \\ School of Maxim, Zhejiang University \\ Hangzhou, China \\ 1xj@zufe.edu.cn
}

\author{
Ma Jianqing \\ School of Maxim, Zhejiang University \\ Hangzhou, China \\ Majq2007@163.com
}

\begin{abstract}
The research about ideological and political education rules plays a leading role in the research about discipline of ideological and political education, and since the discipline is under the development stage, the opinions of different scholars cannot be completely unified. This paper further makes clear the connotation and fields of ideological and political education rules through sorting out above 30 -year theoretical research course of ideological and political education rules on the basis of analyzing and summarizing the various components and basic conflicts of ideological and political education, and then makes the ideological and political education rules more specific in theory, to better guide ideological and political education work in practice.
\end{abstract}

Keywords-Ideological and political education; Ideological and political education rules; Ideological and political education process rules; Basic rules of ideological and political education Introduction

\section{INTRODUCTION}

Throughout above 30 years of theoretical research course of ideological and political education rules in China, it can be found that it has always been the major theoretical subject for the discipline, and has also experienced a process from fuzzy to accurate, from specific to general, from shallow to profound and from simple to rich. From 1980s to the beginning of the century, it can be said as the exploration period for the research about ideological and political education rules, and both the connotation and contents definition are inclined to be specific and diversified, and haven't formed the unified, systematic and in-depth research about the ideological and political education rules yet, but it has laid a solid foundation for the follow-up research. Since 21st Century, along with the further development of ideological and political education discipline and the perfection of relevant theories, the academic circle gradually transits definition of ideological and political education rules to the essential and necessary contact from nonessential and unnecessary contact. The Modern Thought Politic Education (People's Publishing House, 2001 Version) edited by Zhang Yaocan, Zheng Yongting, Liu Shulin and $\mathrm{Wu}$ Qiantao was regarded as the representative work for the true conversion from the research about ideological and political education process to the research about ideological and political education rules[1]. During the period, the research about "ideological and political education rules" has gradually gotten rid of the specific characteristics of ideological and political education work in concept and connotation definition, and can truly reflect compact and profound rules research; in the contents research, system theory starts to be taken as the angle of view, and attentions are paid to the rich integral and hierarchy for all factors of ideological and political education rules.

The research about the ideological and political education rules of these two periods is specifically discussed below.

\section{RESEARCH ABOUT IDEOLOGICAL AND POLITICAL EDUCATION RULES IN 20TH CENTURY}

1980s and 1990s are exactly the beginning for the establishment of discipline, and it is the transit process from "the discussion about ideological and political education work" to "the research about the theory of ideological and political education", and the academic circle hasn't gotten rid of the influence of specific ideological and political work considering the research about ideological and political education rules yet, and has presented specific and meticulous characteristics.

\section{A. Main aspects for the research about ideological and political education rules in 20th Century}

1) Research about the ideological and political education process rules

In works about ideological and political education in 20th Century, the discussion about the ideological and political education rules mainly emphasizes on the aspect of "ideological and political education process rules", such as the Ideological and Political Education Principle written by Zhang Yaocan (Central China Normal University Press, 1988 Version), and the Ideological and Political Education Overview written by Qiu Weiguang (Tianjin Peoples Publishing House, 1988 Version).

Except this, some scholars also put forward the concept of "ideological and political education rules", but as can be seen from the definition and explanation, they fail to fully distinguish it from "ideological and political education process rules". The Ideological and Political Education (1988 Version) written by Chen Baijun had already put forward "ideological and political education rules", and thought that it was requested 
to understand the ideological and political education rules of three basic factors requested to conduct ideological and political education-educator, contents of ideological and political education as well as the necessary contact and conflict movement of educated people in ideological and political education process[2](P2-44) The concept of "ideological and political education rules" here is actually similar to the "ideological and political education process rules" put forward by most scholars at present. Firstly, the three basic factors discussed here can better meet the component factor in the ideological and political education process, and although currently the opinions of academic circle about the component factors in ideological and political education process are inconsistent, the educator, educated people, education contents and education media are generally regarded as the component factors. Thus, the relations and conflicts of these component factors should reflect the ideological and political education process rules; secondly, the concept definition focuses on exploring how can the educators use education contents to generate changes to the political thoughts of the educated people in the ideological and political education process and activities through taking the formation rules for the political thoughts and opinions of the educated people as the basis, and it is more like a kind of overview to the internalization process rules of ideological and political education. However, the proposal of "ideological and political education rules" provides a new direction for the follow-up theoretical research.

2) Research about the specific rules of ideological and political education

In the Ideological and Political Education (1989 Version) edited by Wang Lizhan in Zhejiang University, it started from analyzing the basic conflicts of ideological and political education, and put forward that the basic rules running through the full process and all aspects of ideological and political education are: the rules for directional guidance in conflicts; the rules for development in twists and turns; the rules of hierarchical progression[3](P193-199), and meanwhile, further specifically analyzed various basic rules, and put forward specific requirements for ideological and political education. The Ideological and Political Education Principle (1986 Version) edited by Lu Qingren failed to clearly put forward the concept of ideological and political education rules or process rules, but he pointed out that, ideological and political education should follow the general rules of education, meet the general rules of people's mental activities, and master the general rules of moral generation process, and point out the theoretical framework for the research about ideological and political education.[4](P47-51) The Ideological and Political Education (1990 Version) written by Zhu Xuewen and Xu Taiyong thought that the basic rules of ideological and political education included nine aspects and carried out discussion.[5](P30-56) These researches can exert a positive leading function in carrying out the specific work of ideological and political education at that time, but generally speaking, due to the restriction of discipline development, the theoretical definition of rules at that time was inclined to be meticulous, and lacked in overall generalization, and the research was closer to the principle and method of ideological and political education work.
3) Initial definition about the connotation of ideological and political education rules

In the works of the period, Ideological and Political Education edited by Wang Lizhan put forward "the basic rules of ideological and political education" and defined the connotation. In the book, it is pointed out that: ideological and political education is carried out and realized in both identical and opposite conflict movement process, and this process contains certain rules, and stipulates the basic trend of process development. "Rules are relations", and the contact of essences [3](P193). Such discussion has pointed out the direction for the in-depth exploration about the basic rules of ideological and political education.

\section{B. Analysis about the main characteristics of ideological and political education rules in 20th Century}

Throughout the references of the period, we hold that the research about ideological and political education rules at that time have the following characteristics: firstly, only few works mention "ideological and political education rules", and the research about ideological and political education rules present intermittent and nonsystematic status; secondly, it is inclined to materialization in research, and some researches hold that "ideological and political education rules" are similar to the ideological and political education process rules or the principle, method and requirements of ideological and political education. The reasons why it can present such characteristics may mainly include: firstly, the researchers hold that ideological and political education rules should be reflected in the ideological and political education operation process, and the ideological and political education cannot reflect rules under static status [6]. Thus, some scholars don't strictly distinguish the ideological and political education rules and ideological and political education process rules. Secondly, the ideological and political education in our country firstly has the ideological and political education work and practice, and then the discipline setup and the theoretical research of relative system, the research of rules is also started from the ideological and political work rules and process rules, which can fully meet the reality of ideological and political education development. Thirdly, from "ideological and political education process rules" to "ideological and political education rules", this can also reflect the process from specific research about ideological and political education rules to general theoretical deepening. The research of "rules" corresponds to the research of "relations" and "conflicts" in essence, and in the social practice of ideological and political education, people have certain cognition about various specific relations in various phenomena of ideological and political education by virtue of unique thought and cognition capacity, and then gradually, it will transit to the essential necessary contact from the nonessential and unnecessary contact, and then gradually establish general research about ideological and political education rules. 


\section{RESEARCH ABOUT THE IDEOLOGICAL AND POLITICAL EDUCATION RULES IN 21ST CENTURY}

Along with the scientific and systematic development of ideological and political education discipline, the cognition and explanation of the academic circle have been gradually profound and perfected, and so does the research about ideological and political education rules. The Modernized Ideological and Political Education (People's Publishing House, 2001 Version) edited by Zhang Yaocan, Zheng Yongting, Liu Shulin, and $\mathrm{Wu}$ Qiantao was regarded as the representative work for the conversion of the research about ideological and political education process rules started towards the research about ideological and political education rules. Since $21 \mathrm{st}$ Century, the academic circle has a fast development in the research about the ideological and political education rules, and has an in-depth cognition about ideological and political education rules.

\section{A. The relationship between "ideological and political education rules" and "ideological and political education process rules" starts to get out of the chaos, and becomes clear gradually}

More and more scholars regard "ideological and political education process rules" as one subordinate layer of "ideological and political education rules". In the Basic Principle of Ideological and Political Education written by Sun Qi'ang, it was held that ideological and political education rules are a system, and the ideological and political education process rules along with the rules about the mutual effect between ideological and political education and the society, people's ideological behavior activity rules as well as the construction of ideological and political education system and management rules as the four rules subsystems of ideological and political education rules system.[7](P83) Luo Hongtie and Dong Ya et al. regarded the process rules as one of the specific contents, and regarded the former one as Level 2 rules of the latter one [8]. There are also some scholars holding that these two not only have connections but also differences [9].

Except this, although some scholars haven't clearly explained the relation of the two, they also hold that ideological and political education rules and ideological and political education process rules should be two different concepts and should be discussed separately. Zheng Yongting thought that, the ideological and political education process rules were relatively narrow [6]. In case of mixing these two contents, the research about ideological and political education rules would be narrowed.

To sum up, in the recent years, a consensus has been basically reached considering the concept that "ideological and political education rules" are not equivalent to "ideological and political education process rules". More and more scholars advocate the separation of these two contents; currently, the research of scholars about ideological and political education process rules and ideological and political education rules has been carried out synchronously, and further discussed and clarified the relation of the two. We hold that, the ideological and political education process rules exert function under the guidance and restriction of the basic rules of ideological and political education, and it is the materialization and application development for the basic rules of ideological and political education in some links and some aspects. Meanwhile, the basic rules of ideological and political education can also be extracted from the ideological and political education process rules, and without these process rules, basic rules will become water without source, and tree without roots, i.e., it will lose a solid basic support.

\section{B. The academic circle can basically reach an agreement in the definition basis, theoretical position and concept interpretation of ideological and political education rules}

The current definition of the academic circle about the connotation and contents of ideological and political education rules is basically as per the discussion of Lenin about "rules are relations......the essential relation or relations of essences", and carried out on the basis of the "relations" or "conflicts" for the internal factors of ideological and political education. For instance, although the definition of ideological and political education rules is literally different in the Modernized Ideological and Political Education written by Zhang Yaocan, Zheng Yongting, Wu Qiantao, Luo Yuting et al. (People's Publishing House, 2006 Version),[10](P119) the Basic Principle of Ideological and Political Education written by Sun Qi'ang,[7](P81) the Ideological and Political Education edited by Su Zhenfang and published in 2006[12](P160), and other works, all the respective definitions include two important key words, i.e., "essence" and "relation (or contact)".

This indicates that, ideological and political education factors are complicated and varied, and it is still hard to accurately define the relation or contact of various factors in the current period, but the academic circle has obtained relatively consistent opinions about the definition of ideological and political education rules in concept and the cognition of its leading role (i.e., regard the ideological and political education rules and the essence of ideological and political education as the same layer, and regard "rules" and "essence" as the concept in equal measure).

\section{Have a more systematic and in-depth exploration about the specific contents of ideological and political education rules}

Since the definitions about the internal conflicts of ideological and political education are different, the internal factors and factor relations are different, and the opinions about the ideological and political education objective and tasks are different, the explanations about the occurring field and specific contents of ideological and political education rules are different, too. In the recent years, the research opinions are mainly as follows. 
1) Emphasize on the "single-layer research" about the basic rules of ideological and political education

The so-called "single-layer researches" are specific to "hieratical research", i.e., explain the contents about ideological and political education rules from a single and integrated layer as per the relation for all components of ideological and political education.

For instance, some scholars have summarized three basic rules of ideological and political education: "the rule that ideological and political education must adapt to the social economic relation development; the rule that the educator and the educated people can exert mutual effect; the rule about the spiral increase of ideological and political education process" $[13](\mathrm{P} 75)$ There are also scholars putting forward the two basic rules of ideological and political education: people's thought and behavioral activity changing rules, and the party and state's rules for the people to conduct ideological and political education; meanwhile, it is held that the former one belongs to the range of people's ideological activity changing rules, and the latter one belongs to the range of ideological and political education process rules.[12](P165-173)

The aforementioned theories emphasize on "the basic rules" of ideological and political education, but there are no explanations about correspondingly "specific rules".

2) Divide ideological and political education rules into the "double-layer research" of "basic rules" and "double-layer research"

Based on the hierarchy of conflicts, many scholars have conducted hierarchical definition about the contents of ideological and political education rules, and divided ideological and political education rules into basic rules and specific rules, of which the research of Zhang Yaocan and Zheng Yongting is the most representative.

In the Modernized Ideological and Political Education (2001 Version), Zhang Yaocan, Zheng Yongting and other scholars put forward the opinion of "the hierarchical research about the ideological and political education rules", and meanwhile, divided the ideological and political education rules into the basic rules and specific rules of ideological and political education for discussion, and put forward the basic rules of ideological and political education, the concept and connotation of specific rules.[14](P66-80) In the follow-up works, further explained the basic rules and specific rules of ideological and political education, and held that there were two basic rules of ideological and political education: the ideological and moral formation development rules; following and serving the social development rules. But "the specific rules of ideological and political education can reveal the essential contact of certain type, certain part, and certain link of ideological and political education."[10](P119-130)

The aforementioned researches have accurately defined the ideological and political education rules, the basic rules of ideological and political education and the specific rules of ideological and political education, and systematically revealed the connotation of these rules; of which the proposal about the specific rules of ideological and political education has provided thoughts for the further in-depth research of ideological and political education rules.

3) Regard ideological and political education rules as a "systematic" "multi-layer research" (systematic research).

The Basic Principle of Ideological and Political Education written by Sun Qi'ang held that, ideological and political education rules are a system, and it was requested to "put ideological and political education into the entire social system for operation" , and also held that, the ideological and political education rules system included four rule subsystems, and each subsystem has specific hierarchy.

Luo Hongtie put forward that it was requested to study ideological and political education rules through regarding it as a system as per the opinions of system theory, and put forward the following assumptions: regarding ideological and political education rules as Level 1 rules (which was also called as macroscopic rules), and the subsystem for the ideological and political education rules system was Level 2 rules of ideological and political education (which was also called as mesoscopic rules), and Level 2 rules of ideological and political education rules had its own subsystem, and these subsystems constituted Level 3 rules of ideological and political education (which was also called as microcosmic rules). [1]

The hierarchical research (systematic research) about ideological and political education rules is the direction for current research about ideological and political education rules. We hold that, the aforementioned researches are mainly researches about the rules occurring field, and it is still requested to further discuss the specific contents of rules, for instance, in essence, "people's ideological behavior rules" indicate one occurring field of ideological and political education rules, but how to let such rules reflect and exert functions among different individuals and under different scenes is the contents that request follow-up research. It can be said that, the existing hierarchical research about ideological and political education rules can provide the mainline and foundation for exploring the specific contents about the ideological and political education rules, with important theoretical guidance significance.

\section{FUTURE RESEARCH PROSPECT OF IDEOLOGICAL AND POLITICAL EDUCATION RULES}

To sum up, the research of the academic circle about the ideological and political education has obtained relatively rich effect, but due to reasons such as relatively short discipline establishment time, and the complicity of ideological and political education, the research about ideological and political education has certain divergence in many aspects. It is inevitable for the theoretical development of discipline to experience a process from chaos to clear, from the surface layer to the essence and from the contention of a hundred schools of thought to gradual unification. From the perspective of discipline development, as the important field for the theoretical research of ideological and political education, on the basis of the former researches, the follow-up research about ideological and political education should follow the following thoughts. 
A. Clear up the various components and relations of ideological and political education, and further make clear the basic connotation of ideological and political education.

It is commonly held by the academic circle that, ideological and political education rules and the essence of ideological and political education belong to the same layer, and the research thereof should be started from the internal relations for various factors of ideological and political education. Rules are things that already exist but will not be under the subjective influence of the researchers, so it should be confirmed and unified. However, since the discipline of ideological and political education is now developing, and the academic circle fails to unify the component factors, main conflicts and other cognitions of ideological and political education, it has made the definition and research about "ideological and political education rules" present the flourishing status with the contention of a hundred schools of thought. Just as what said by Zheng Yongting, "up till present, it was hard to obtain consistence in ideological and political education rules, especially the basic rules of ideological and political education. Besides, the relations of ideological and political education rules, ideological and political education science rules, and ideological and political education process rules were not fully understood.'[6] We have found out that, the difference for the current ideological and political education rules, ideological and political education process rules and the connotation of ideological and political education rules is still quite fuzzy to some extent, and on one hand, scholars hold that, the concepts should be different, and they have tried to distinguish them, but on the other hand, they lack in more in-depth and specific discrimination. This has made the research about ideological and political education rules get into a more complicated status. The confirmation about the connotation of ideological and political education rules requires the clarification of all component factors of ideological and political education and the complicated relations of various factors, and this has made the ideological and political education rules different from other rules, and except the characteristics of "rules", it can also reflect the uniqueness of "ideological and political education".

\section{B. Straighten out the main aspects and minor aspects of} conflicts in ideological and political education, and further unify the basic field and derivation field for the occurrence of ideological and political education rules.

As per the opinions of conflict theory, the main aspects of conflicts can lead the direction for the development of things, and the minor aspects of conflicts will influence the overall situation through the local influence or the influence of certain link. The ideological and political education itself is a system constituted by various factors under complicated operation, and it is also applicable to conflict theories. The necessary approach to explore ideological and political education rules is to analyze the conflict movement in ideological and political education system, and clarify the main aspects and minor aspects of conflicts. The opinions about the main conflicts and minor conflicts of ideological and political education are inconsistent, which have caused the different opinions about the occurring field of ideological and political education rules, especially for the hieratical research about rules, which can reflect this point more. Discussions such as "the basic rules of ideological and political education" is "the rules for the formation development of thought and qualities", "following and serving the rules of social development" are essentially the definition of basic fields about the ideological and political education rules, and have divided the specific fields about the research of ideological and political education rules. The definition of different rules fields will correspond to the interpretation of different rules contents. The follow-up research should further clarify the main aspects and minor aspects of conflicts in ideological and political education, and ideological and political education is regarded as a system to conduct hieratical research, explore the rules field of macroscopic, mesoscopic and microscopic layers, and make the research about all levels of ideological and political education rules more comprehensive and perfect.

\section{In combination with the specific field for the occurrence of ideological and political education rules, conduct more specific and in-depth research and interpretations in different layers.}

The confirmation of rules field can provide clear direction and task for the research about rules, but merely the division of rules field is not sufficient enough, it is also requested to further explain and describe the contents of rules on this basis. As can be seen from the current research achievements, the researches about the contents of ideological and political education rules are mostly kept at the layer of rules occurring field, and the hieratical research about rules is mainly the research about the rules occurring field of different layers (the main layer and specific layer), for instance, as one of the ideological and political education rules held by scholars"thought formation and changing rules", it is essentially the definition of rules occurring field, but what is "the thought formation and changing rules" exactly, and how to elaborate and summarize as per the characteristics of the subject and other problems should be further studied and made clear in theory. Specific to the research about the rules field, the research about the contents of rules is more specific and complicated, for instance, due to the different subject characteristics, social development degree and other factors, "the thought formation and changing rules" can also present different characteristics, but no matter how complicated these details are, there is always a main line running through it, and there is always a common characteristic to find, and this is also the precondition to study the contents of rules. After the contents of rules are further defined, rules will have higher practical guidance significance with stronger pertinence. 
D. Take the theoretical research of ideological and political education rules as the precondition, apply ideological and political education rules in practice, and further promote the effectiveness of ideological and political education.

Theories are originated from practice and can also guide practice, and as a work in China, ideological and political education has already had several years of experience. But a better education effect can only be obtained through exploring and finding the ideological and political education rules, and truly applying these rules in the practice of ideological and political education work. Thus, while constantly perfecting the theoretical research about the ideological and political education, it is requested to explore how to truly apply rules in the practice of ideological and political education work. When following the ideological and political education rules in practice, it is also requested to adjust measures to local conditions, and specifically analyze specific problems, and do not apply mechanically. In the recent years, along with the development of new media and information technology, ideological and political education have also been expanded to a broader field taking network as the carrier, and how to apply education rules in these fields is also the contents that are in urgent need to be studied.

\section{ACKNOWLEDGEMENT}

About the Author: Li Xiaojuan, the Doctoral Student for the School of Marxism, Zhejiang University and the Associate Professor for the School of Marxism, ZUFE (Hangzhou, Zhejiang 310007); Ma Jianqing, the Professor and Doctoral Supervisor for the School of Marxism, Zhejiang University. (Hangzhou, Zhejiang 310028)

Project Fund: Zhejiang University Moral Education and Student Development Research Center Project "Research about the Basic Theory of contemporary Ideological and Political Education" (Project No.: DZ201302); Ministry of Education Humanistic and Social Science Research Project "Research about the Psychological Health Education as well as Ideological and Political Education in Combination with 30year Gain and Loss" (Project No.: 16YJA710017)

\section{REFERENCES}

[1] Luo Hongtie. Review and Prospect for the Research about Ideological and Political Education Rules [J]. Studies in Ideological Education, 2009 , (1)

[2] Chen Baijun. Ideological and Political Education [M]. Dalian: Press for Dalian University of Technology, 1988.

[3] Wang Lizhan. Ideological and Political Education [M]. Hangzhou: Zhejiang University Press, 1989.

[4] Lu Qingren. Principle of Ideological and Political Education [M]. Shanghai: Fudan University Press, 1986

[5] Zhu Xuewen and Xu Taiyong. Ideological and Political Education [M]. Beijing: Maritime Press, 1990, (11).

[6] Zheng Yongting. Process and Summary about the Basic Theoretica Research of Ideological and Political Education [J]. Studies in Ideological Education, 2014, (4)

[7] Sun Qi'ang. Basic Principle of Ideological and Political Education [M]. Nanjing: Hohai University Press, 2004.

[8] Luo Hongtie and Dong Ya. Basic Theoretical Research about the Principle and Method of Ideological and Political Education [M] Beijing: People's Publishing House, 2005.

[9] Fei Ping. Historical Tracing and Future Expectation about the Research of Ideological and Political Education Process Rules [J]. An Study on Ideological and Political Education, 2013, (10).

[10] Zhang Yaocan, Zheng Yongting, Wu Qiantao, and Luo Yuting. Modernized Ideological and Political Education [M]. Beijing: People's Publishing House, 2006.

[11] $\mathrm{Hu}$ Mo and Sun Qi'ang. Philosophical Field of Ideological and Politica Education Rules [J]. Jianghan Tribune, 2004, (8).

[12] Su Zhenfang. Ideological and Political Education [M]. Beijing: Social Sciences Academic Press, 2006.

[13] Cang Daolai. Ideological and Political Education [M]. Beijing: Peking University Press, 2004.

[14] Zhang Yaocan, Zheng Yongting, Liu Shulin and Wu Qiantao. Modernized Ideological and Political Education [M]. Beijing: People's Publishing House, 2001

[15] Zheng Yongting. Research about the Basic Rules of Ideological and Political Education-Scientific Reveal of Marxist Historica Materialism [J]. Journal of Ideological \& Theoretical Education, 2001, (1)

[16] Luo Hongtie and Wang Li. Evaluation and Analysis about the 30-year Development of Ideological and Political Education Process Theory. School Party Construction and Ideological Education, 2014, (7).

[17] Feng Gang and Zheng Yongting. Research Report about the 30-yea Development of Ideological and Political Education Discipline [M]. Beijing: Guangming Daily Press, 2014. 